\title{
Reframing Water Efficiency: Determining Collective Approaches to Change Water Use in the Home
}

\author{
Claire Hoolohan ${ }^{1^{\star}}$ and Alison L. Browne ${ }^{2}$ \\ ${ }^{1}$ Tyndall Centre for Climate Change Research, University of Manchester, M13 9PL, UK. \\ ${ }^{2}$ Sustainable Consumption Institute / Geography, University of Manchester, M13 9PL, UK.
}

Authors' contributions

This work was carried out as part of the empirical research toward a doctoral thesis. Author $\mathrm{CH}$ designed the study, carried out the fieldwork and data analyses, and wrote and revised the manuscript. Author ALB supervised the project and contributed to the study design and implementation, supported the analyses and reviewed and edited the manuscript. Both authors read and approved the final manuscript.

Article Information

DOI: 10.9734/BJECC/2016/18187

Original Research Article

Received $8^{\text {th }}$ April 2015 Accepted $20^{\text {th }}$ October 2015 Published 25 ${ }^{\text {th }}$ August 2016

\section{ABSTRACT}

Aims: This paper explores the collective ordering of domestic water use, shaped through shared social, technical and natural relations, and outlines how this understanding can be used to inform water efficiency initiatives in order achieve sustainable domestic water consumption.

Study Design: Literature review, focus group and qualitative data analysis.

Place and Duration of Study: South of England; December 2013.

Methodology: Three focus groups were held with consumers in the south of England. Each group comprised of 5-8 participants, strategically sampled for a mix of genders and metered/ unmetered customers, and split by life-stage (where age was used as a proxy; 21-35, 36-50, 50+). In-depth, semi-structured discussion techniques were used to investigate the collective drivers of everyday water use and the impact of water efficiency initiatives in changing patterns of water use in the home.

Results: Four key drivers are identified: 1) expectations of service and supply; 2) decision making 3 ) social norms and networks and 4) socio-technical practices. The findings reveal that while evidence of all drivers are identified in focus group discussions, some offer greater value for intervening in household consumption than others. The discussion uses the example of household laundry to explore the implications of this research for informing water efficiency activities.

Conclusion: Achieving sustainable domestic water consumption requires fresh thinking about water use as a collectively ordered activity. The approach taken highlights alternative spaces for intervention and the findings of this research sheds light on the efficacy of existing water efficiency 
activities in bringing about more sustainable domestic consumption. The implications of this research are a shift away from providing information and incentives, toward building a more transparent and open relationship with consumers about water resources and developing the resources to identify and address broad social and technological trends that inhibit behavior change.

Keywords: Water efficiency; demand management; social practices; collective action.

\section{INTRODUCTION}

Over the last decade headway has been made in establishing and developing an agenda for demand management across the water industry of England and Wales to enhance the security and sustainability of water supplies now and into the future. Typically activities are characterized by two streams i) infrastructural development to enhance supply efficiency and ii) water efficiency initiatives to reduce domestic consumption [1]. There is uncertainty regarding how climate change, population growth and other social changes will shape future water demand [2]. To address these emerging challenges the water industry is increasingly referring to approaches that intend to transform demand; from collaborative efforts to reconfigure everyday water consuming practices right through to developing collective infrastructures (e.g. water grids). This push towards discourses of 'collectives', 'collaboration', and 'cooperation' raises important questions for policy makers and managers; how can we understand water consumption as a collectively ordered activity? And how can we use the collective drivers of consumption to reduce household water demand? From an academic perspective it is important to critically consider the types of 'collectives' enacted through water efficiency campaigns, and whether or not these forms of interventions can create substantive long-term change towards sustainable water management.

This positioning of consumption as a collectively ordered activity reflects developments in the social science literature that push back on conventional approaches to sustainable consumption which prioritizes the individual [3-6]. Such approaches fail to account for the complexity of demand; embedded in household technologies, social meanings, cultures, infrastructures and institutions that shape and maintain everyday water use $[7,8]$. In recent years a number of alternative social science perspectives have emerged which celebrate the collective, relational nature of demand [9-12]. However this is far from a consensual body of literature. The purpose of this paper is to present an analysis of various paths that could be, and are being, taken to mobilizing collective action in order to achieve sustainable domestic water consumption in the UK, and to evaluate the salience of these in the experiences of consumers in the south of England.

The following section provides a critical analysis of literature from across the social sciences, synthesizing these diverse and divergent works into four perspectives that reflect how demand might be understood as a collectively ordered activity and demonstrate the consequences of these for water efficiency activities (Table 1). A brief methodology follows in section 3. Section 4 presents findings from focus group research evaluating the role of these collective drivers in shaping water use in the home, identifying the opportunity for, and efficacy of, different paths to sustainable domestic water consumption. Using these perspectives as the basis for analysis, the focus group data reveals that each perspective highlights different drivers of demand; different sites, scales and subjects to which water efficiency campaigns might attend; and different opportunities for intervention, some with greater potential to bring about sustainable domestic water consumption than others. The discussion, Section 5, focusses on laundry as a specific example of domestic water use to demonstrate how taking an approach informed by this notion of 'collective' opens up new opportunities for intervention.

\section{WHAT ARE THE COLLECTIVE DRIVERS OF DEMAND?}

This section critically analyses various social science literatures that provide insight into how everyday consumption may be understood as a collectively ordered activity. This suggests consumption is shaped and maintained by shared and collective drivers that consumers have varying degrees control over, connected variously to different spatial-temporal sites and scales. The findings are synthesized into four perspectives that describe demand as a product 
of i) service provision; ii) individual decision making; iii) social norms and networks; and finally iv) socio-technical practices. The following paragraphs outline each perspective and Table 1 demonstrates the consequences of each perspective for the principles and practices of water efficiency.

Each perspective has implications for the framing of water efficiency, and subsequently on the types of initiative likely to be undertaken. The possibilities for management activity are discussed (some of which are more commonly realized in existing practice than others). Importantly, while each offers potential routes for the management they engage with different contextual drivers of water demand in the home and are therefore likely to have varying degrees of effectiveness. The salience of each of these perspectives in the experiences of consumers in the South of England is evaluated in Section 4.

The first perspective conceptualizes demand as product of service provision, driven by the activities of the water industry, ongoing and historical. Current demand emerges from institutional and infrastructural development of water resources designed to accelerate the public health agenda throughout the twentieth century [13-16]. While privatization in 1989 may have shifted responsibility for service provision into the hands of water companies, the presiding strength of structural engineering logics and the modern regulatory structure reinforces this history. From this perspective demand is coordinated through the organizations responsible for the regulation and management of water. Possible interventions include the engineering supply to accommodate rising demand and unpredictable future conditions (e.g. through leakage reduction and network development); and/or transparently and ubiquitously communicating the limits to supply security (e.g. through planning, construction and manufacturing regulation, and through pricing structures). Currently, the service provision model is embedded in a top-down approach to water management, however this model could be adapted to cultivate a resilient society, ensuring adequate preparation for unknowable and potentially disastrous events $[17,18]$.

The second perspective presents demand as result of individual decision making; the sum total of individual choices regarding water use in the home, influenced by variables such as attitudes (e.g. towards conservation), situational factors (e.g. income, tenancy arrangement), and perceived ability to take action and have influence [19]. The emergence of this position within the water industry is a result of the increasingly proactive positioning of consumers in line with a broader rhetoric on sustainable consumption. From this perspective the collective drivers of demand are common values which influence large swathes of the population, particularly price which is a commonly reported motivator of water conservation [20]. Possible interventions include the provision of simple, cost-effective solutions and complementary incentives to make better decisions in the home [21]. Such interventions can be effective however they are problematic as they do not address the socio-technical landscape in which consumption is situated or challenge accepted standards of supply and demand. Thus, per capita consumption is likely to remain on an upward trajectory and combined with rising populations any short term reductions are likely to be offset, with limited long term benefits to supply resilience [22].

The third perspective emphasizes social norms and networks as influences on individual decision making. Clark and Finley [23] demonstrate that individual intentions are more likely to translate into action if they are supported by others around them. Furthermore individuals seen to be indirectly influenced by their understanding of what is normal and acceptable both in terms of everyday water use, and uptake of new technologies, behaviors and routines (e.g. Lam [24] demonstrates that people are more likely to install duel-flush toilets if it is perceived to be common practice). More broadly consumer decisions are presumed to be informed by underlying beliefs or ecological world views; such as whether consumers perceive water to be a scarce resource or whether they believe their actions have any impact $[19,25,26]$. From this perspective possible interventions involve working within social networks to provide social and moral justification for change. As is the case above actions such as these are unlikely to be sufficient to offer long term solutions, however interventions may also encourage the political momentum within communities to support wider action and thereby increase the confidence and ability of communities to take action. 
Table 1. Four perspectives on collective approaches to water efficiency

\begin{tabular}{|c|c|c|c|c|}
\hline \multirow{2}{*}{$\begin{array}{l}\text { Implications } \\
\text { for water } \\
\text { efficiency }\end{array}$} & \multicolumn{4}{|c|}{ Four collective approaches to water efficiency } \\
\hline & Service provision & Decision making & $\begin{array}{l}\text { Social norms \& } \\
\text { networks }\end{array}$ & $\begin{array}{l}\text { Socio-technical } \\
\text { practices }\end{array}$ \\
\hline $\begin{array}{l}\text { What are the } \\
\text { collective } \\
\text { drivers of } \\
\text { demand? }\end{array}$ & $\begin{array}{l}\text { Industry activities; } \\
\text { institutionalized } \\
\text { understandings about } \\
\text { water resources. }\end{array}$ & $\begin{array}{l}\text { Price and other use } \\
\text { variables commonly } \\
\text { valued by } \\
\text { consumers. }\end{array}$ & $\begin{array}{l}\text { Socially defined } \\
\text { standards of } \\
\text { normal and } \\
\text { acceptable use. }\end{array}$ & $\begin{array}{l}\text { Collective } \\
\text { conventions; } \\
\text { everyday routines; } \\
\text { technologies and } \\
\text { infrastructures. }\end{array}$ \\
\hline $\begin{array}{l}\text { Principles } \\
\text { of water } \\
\text { efficiency }\end{array}$ & $\begin{array}{l}\text { Demand must be } \\
\text { managed on behalf } \\
\text { of consumers or } \\
\text { need to re-establish } \\
\text { limits to supply } \\
\text { security under } \\
\text { uncertainty \& } \\
\text { extremes. }\end{array}$ & $\begin{array}{l}\text { Given the right } \\
\text { incentives and tools } \\
\text { consumers are likely } \\
\text { to make better } \\
\text { decisions. }\end{array}$ & $\begin{array}{l}\text { Consumers can be } \\
\text { influenced through } \\
\text { moral and } \\
\text { normative } \\
\text { reasoning to make } \\
\text { better decisions. }\end{array}$ & $\begin{array}{l}\text { Socio-technical } \\
\text { drivers limit the } \\
\text { extent of } \\
\text { consumers' ability } \\
\text { to control water use } \\
\text { in the home. }\end{array}$ \\
\hline $\begin{array}{l}\text { Water } \\
\text { efficiency } \\
\text { activities }\end{array}$ & $\begin{array}{l}\text { - Improving mains } \\
\text { efficiency \& } \\
\text { leakage. } \\
\text { - Abstraction reform. } \\
\text { - Re-connecting } \\
\text { supply to natural } \\
\text { conditions (e.g. } \\
\text { seasonal tariffs). }\end{array}$ & $\begin{array}{l}\text { - Communicating } \\
\text { costs of inaction. } \\
\text { - Designing } \\
\text { incentives (e.g. } \\
\text { billing \& smart } \\
\text { metering). } \\
\text { - Providing advice } \\
\text { (e.g. water saving } \\
\text { tips). } \\
\text { - Offering products } \\
\text { to ease change } \\
\text { (e.g. water efficient } \\
\text { devices). }\end{array}$ & $\begin{array}{l}\text { - Engaging } \\
\text { communities and } \\
\text { social groups. } \\
\text { - Communicating } \\
\text { positive, normal } \\
\text { practices (e.g. } \\
\text { comparative } \\
\text { billing, normative } \\
\text { messaging) } \\
\text { - Offering products } \\
\text { to ease change } \\
\text { (e.g. shower } \\
\text { timers). }\end{array}$ & $\begin{array}{l}\text { - Re-designing / } \\
\text { diversifying } \\
\text { systems of } \\
\text { provisioning (e.g. } \\
\text { rainwater } \\
\text { harvesting). } \\
\text { - Re-configuring } \\
\text { water in the home } \\
\text { (e.g. drought } \\
\text { resistant } \\
\text { gardens). } \\
\text { - Changing routines } \\
\text { (e.g. white } \\
\text { uniforms in } \\
\text { warehouse work). }\end{array}$ \\
\hline
\end{tabular}

The fourth perspective presents demand as an effect of socio-technical practices, hereby departing from psychological perspectives, typically with vociferous criticism [3]. From this perspective domestic water consumption is mundane and inconspicuous, entangled the continual achievement of everyday life [27,28]. Rather than being guided by explicit values and beliefs consumption is guided by collective conventions; "shared, accepted ways of doing things" [27] which are coproduced with water provisioning infrastructures and household technologies; intangible meanings around, for example, cleanliness and convenience; and tacit, experiential understanding and skills that reflects ways of doing. Furthermore domestic water demand is implicated in the organization and coordination of everyday life for example parenting, work and leisure, each with their own associated collective conventions [29]. From this perspective the collective drivers of demand are a diverse array of socio-technical relations which produce patterns of consumption. Consequently potential intervention must engage with areas as diverse as design, planning, workplace relations and industry standards [10]. The attribution of water savings resulting from interventions such as these is difficult to isolate, resulting from indirect action taken to shape the context of individual behavior. Consequently they require sophisticated forms of monitoring and evaluation, yet such interventions are likely to be conducive to achieving sustainable domestic water consumption.

The paragraphs above provide a condensed account of what is a voluminous and conflicting body of literature. The achievement of this section has been to align some of the most powerful perspectives in contemporary resource management and relate them to a common topic; collective action. This enables the transparent analysis of consumption and intervention as they appear through various theoretical lenses, a generosity which could not be afforded by a single-discipline approach. Table 1 also 
highlights examples of where these perspectives find traction in specific water efficiency activities. Such analysis reveals the extent of investment across the water industry and highlight potential areas of opportunity not being addressed. The following section explores these perspectives through the everyday actions and experiences of consumers, through focus group data.

\section{METHODS}

This paper presents findings from the first stage of a mixed methodology approach to studying collective divers of consumption within one water company boundary. The main research method was focus groups held with residents of a town in the south of England. Average per capita consumption in this region is 143 liters per day $(\mathrm{l} / \mathrm{d}), 10 \%$ higher than the Government's vision for sustainable demand [30], and the reliance on abstraction from local chalk stream ecosystems to meet this demand is cause for concern. Subsequently the town is centerpiece of a largescale water efficiency initiative, organized by the regional water company in partnership with numerous local and national stakeholders.

The aim of the focus groups was to explore everyday consumption and the impact of targeted intervention on domestic water use. Three focus groups were held, each comprised of 5-8 participants, strategically sampled and split by life-stage (where age was used as a proxy; 21-35, 36-50, 50+). Previous research shows life-stage to be the most significant influence on water use in the home, connected to property size, occupancy and routines of the household [9], thus the groups were structured to elucidate heterogeneity within similar social groups. A recruitment company was used, in-line with the University of Manchester ethics protocol, to recruit a mix of genders, employment characteristics and metered/ unmetered customers representative of the regional population.

In-depth, semi-structured discussions were used to identify the drivers of how, when, and how much water was used; and the impact of initiatives and other factors in changing patterns of water use in the home. The discussions centered around two exercises. In the first, participants were asked to reflect on their recognition of, and response to, various water efficiency initiatives in their area. For the second, participants were asked to select from a range of cards those which best represent everyday behavior in a scenario where they were required to reduce everyday consumption to $130 \mathrm{l} / \mathrm{d}$ (in line with industry targets). This required participants to work as a group to negotiate their way to an account of normal and acceptable use of water in the home. While the outputs were revealing the purpose of this test was to provide a platform for discussion of mundane and trivial activities in everyday life to identify the drivers of demand. The focus groups were recorded, transcribed, and coded using the qualitative software package Atlas TiтM focusing on drawing out the drivers and context of everyday water use. The findings demonstrate the role of different drivers from each of the perspectives outlined above and how they impact on the efficacy of actions taken to intervene in household water use.

\section{FINDINGS: WHAT DO CONVERSA- TIONS ABOUT NORMAL CONSUMP- TION REVEAL ABOUT THE COLLECTIVE DRIVERS OF DEMAND?}

\subsection{Service Provision}

Privatization reframed the water industry as a customer-service based industry, redefining the public as paying customers with associated responsibility for their consumption [4,31-33]. However discussions reveal that from the consumers' point of view the consequences of privatization were less simple. The findings presented here are broadly consistent with Haughton's observation that following privatization "the public still chose to view water as a public good, not a private commodity" (1998, p.421). In some cases participants still referred to 'rates' and 'the water board', common references to pre-privatization model of charging for water. For others, while the contemporary charging system was understood, rather than paying for access to a commodity, this was seen to authorize access to secure, high quality supply. This has implications for water efficiency activities too:

"You can't be told what water you can use, you're paying for it, you use how much you want to pay for" (Stuart, 41).

In addition to justifying consumption, the system of billing served to distinguish between water in the home and water elsewhere. A recurring example offered by participants in the focus groups was the paradox between supply maintenance; where leaks were perceived to be 
frequent, often visible and disruptive, yet consumer focused campaigns continue to ask consumers to stop wasting water. While in most cases consumers accepted responsibility for household use, they saw leakage as contradictory to water efficiency activities, and a poor reflection on the service they expect from their bills. Due to the interconnected nature of water resource management problems this division of responsibility is problematic. This is particularly the case when impacts of behavior are indirect, or separate from peoples' everyday experiences [34] Examples of this include practices leading to 'fat-bergs'; a result of residual fat and other materials that go down the plughole in homes but combined cause blockages in sewer systems [35].

When extreme events occur (e.g. drought or flood) consumers are quick to blame the water industry for mismanagement. Thus water companies are seen to inherit the responsibility for securing supplies, now and into the future, and for managing sustainable domestic water consumption as custodians of the natural system. Consequently the most appropriate forms of intervention were deemed those taken on behalf of consumers. In some cases there is acceptance that this may require challenging current standards of consumption (e.g. rationing) but more importantly requires transparent communication of the natural system with consumers.

Graham: but see would it have gone dry if [the water company] sorted the leaks out? Phil: they killed the river! Graham: Going back to the last drought, they brought the hose-pipe ban in far too late, they knew there was a serious problem and they just left it!

Evidence of support for the service provision perspective has profound implications for intervention. As long as the current service arrangement sustains 'top-down' activity is likely to be a fundamental part of achieving sustainable domestic water consumption. Strong regulation and supply development may play a part in this; however our data suggests the most valuable interventions may lie in the development of a positive relationship with consumers, creating a visible presence for the values that water companies are trying to promote (e.g. fixing leaks quickly, repairing landscape around maintenance sites), and building resilience through the customer-supplier relationship prioritizing transparency, consistency and trust. In the face of increasing turbulence and significant uncertainty it may require re-evaluating the service arrangement to develop a more responsive system of supply and demand.

\subsection{Decision Making}

As anticipated, participants were quick to discuss the importance of reducing household overheads, in particular making connections between hot water and potential savings on energy bills. Correspondingly people were supportive of a recent water efficiency campaign sporting the slogan "Free savings, no catch" describing it as eye-catching, simple, clean and entertaining (it was accompanied by a picture of empty fishing tackle). However the relationship between price as motivating intent and a driver of action is complex. While participants demonstrated a clear understanding of paybacks and trade-offs feeding into their considerations on household spending, the low price of water undermines the perceived potential value of technological investments, even where water efficient devices were offered for free:

"It would have to be more than $£ 20$ a month, I'm not rich or anything but that's one takeaway for four and I'm thinking l'd rather not have the take-away than worry." (Vladi, 40).

Reasoned action is further inhibited by the widespread use of direct debits and lowfrequency billing. However, more importantly the findings highlight the low level of consideration given to water use, instead water consuming behaviors are highly automated and habit [36].

"I don't sit there thinking I'm going to have a ten minute shower, I just shower" (Sian, 32).

Secondly water plays diverse and invaluable roles in everyday life, such as preparing for work, looking after children, keeping the house in order, and relaxing:

"That's my time out, shut the bathroom door and that's quiet time, I have a bath too, so I'm probably really bad, but there is no way I could shower in four minutes." (Helen, 34).

As a result water use becomes necessary, not open to reasoning or deliberation: 
"I mean a shower isn't exactly wasting water if you ask me, it's essential, you know, [...] and if I'm going to be in there for a minute longer than l'm told to by a timer, then I'm going to be in there a minute longer." (Phil, 51).

The evidence from these discussions is unanimous, as much as people agreed that saving money was an incentive for water saving, this does not translate to conservation. These findings suggest that future price increases will disproportionately affect those on lower incomes while providing an insufficient incentive for the average consumer to alter consumption. Perhaps counterintuitively, for those who can afford it, increasing the price of water is likely to further legitimize everyday consumption making behavior further resistant to water efficiency advice and information. This poses significant challenges to the water industry. Resource managers rapidly need to address the emphasis placed on price as an influence on decision making, and more broadly on decision making as a collective driver of behavior as consumers are habitual, instinctive and diverse in their consumption.

\subsection{Social Norms and Networks}

Throughout discussions there was evidence of social and moral influences on participants' behavior. There was some evidence of environmental values and beliefs, cited as key predictors of sustainable water consumption [25] but more importantly was evidence of social comparison delineating the boundaries of acceptable water use. Consumers reflected on the visible behaviors of friends and relatives, but also on their experiences abroad where scarcity is more visible (e.g. Turkey \& Greece), the price is higher (e.g. Czech Republic), or different technologies are available (e.g. aeration in Germany).

Social networks play a particular role in learning about new technologies and behaviors [37,38]. During the focus groups lengthy discussions revolved around sharing experiences (e.g. of washing clothes in a fuller wash or on a different setting), and questioning technologies such as rainwater harvesting and water butts; how to obtain them and first-hand reviews of others' experiences. These exchanges pose an opportunity for consumers to share experiences; enabling challenge, reassurance and in some cases the acceptance of previously controversial alternatives, for example see how Phil's attitude shifts in the following:

Neil: Could we use water free cleaners [to wash the car]? Phil: Another bloody product! Does it cost a lot of money? Neil: No, they're quite cheap! Phil: How do you get mud off? Neil: Squirt it on, wipe it off and it just comes up. Zoe: Wipe it off with what? Neil: A cloth! Zoe: Any cloth? Neil: yeah, a micro cloth ideally. Val: So is everybody happy with water free cleaners? Bridget: No. Phil: Why, it sounds a good idea?!

Current approaches using social norms and networks tend to focus on providing information about social norms (e.g. Icaro Consulting [39]), for instance participants had received comparative bills which compared their household usage with other similar households. Despite lack of recognition when prompted these were received with interest, however like the criticisms in the previous section, this did not reflect intention for action.

"Without being to blasé I use the water that I use because that is how live. I think if you came and told me I was four or five times over what people in my situation should be, I might feel a little bit bad then, but I still probably wouldn't change." (Stephen, 31).

The problems with the comparative bill lie in the critique above, the assumption that once given proper information and incentive (in this case, normative as well as financial) people will make better decisions. The discussions demonstrated that behavior poorly connects to explicit processes of social comparison. Despite significant variation between people's everyday behaviors most differences were accepted by the groups without challenge, with only a few exceptions (e.g. participants in one group were shocked regarding the ownership of a Jacuzzi by one participant and another's preference for regular baths - at least one a day - over showers). While these reactions indicate some limits to the boundaries of acceptable behavior, consumers possessing these water intensive technologies and behaviors considered themselves to be normal.

From the evidence collected, more important was the experiential process of learning consumers gain throughout their lives, including interaction with places, people and objects throughout their 
life-course which informed their sense of acceptability:

"I was brought up in Ireland in the fifties, in the countryside, and I had to walk a mile to a well for drinking water, and then a mile home again. My grandparents washed their cloths in a stream by their house, so l've always respected water" (Bridget, 63).

Social networks and norms are powerful yet complex shared and collective drivers of water use in the home. Discussions reveal that to some extent practices of consumption are learnt through explicit discussion and reflection which can be simulated, revealing an opportunity for intervention by creating new spaces for people to interact and provoking conversations around alternative ways of doing (e.g. Thames Water's Fit to Drink campaign). However less tangible experiences of people, objects and places also shape consumption and without efforts to address broad cultural conventions interventions are unlikely to have the scale of impact required to bring about sustainable domestic consumption.

\subsection{Socio-technical Practice}

So far we have touched on the collective drivers of consumption as having socio-technical elements which prevent economic and normative drivers achieving their full potential. This section draws such elements into the limelight to see what opportunities are revealed. Most importantly is the recognition that consumers are not entirely in control of their water use, rather it is entangled in the design and construction of homes and technologies.

"In the morning, I turn the shower on and because its comes from the hot water cylinder maybe twenty feet away, its cold, and I have to wait for the water to warm up." (Phil, 51).

These are not only seen as things that are difficult for consumers to overcome, but in some cases things that consumers shouldn't overcome as designers and manufacturers are seen to be specialists in delivering water to the standards of everyday life.

Phil: I don't want to put something up my tap, I don't, if it was supposed to be there then why didn't the tap manufacturers put it on there in the first place. Bridget: I agree with that if something goes on your tap it is going to make life worse for you.

Thus domestic consumption is partially determined by infrastructure and technologies produced by designers, manufacturers and builders, they in turn producing technologies inline with societal perceptions of normal and modern. People's perceptions of technologies as fitting with ideas about the modern home are made clear when discussing alternative technologies. Significantly, technologies are seen as acceptable if they do not disrupt existing configurations, with the most commonly cited reason for not installing a new technology relating to appearance, fit or involving "tearing up the bathroom.

"I'm thinking of having [a duel flush toilet] fitted anyway in our house, they're nice and modern" (Alison, 41).

There is also a subtle distinction about 'backward' technologies, those which are seen to inconvenience the user, inhibiting access to standards of water use.

"We're supposed to go forward with technology, not backward" (Kim, 52: rainwater harvesting).

These observations show that practices are resistant to change; yet this does not mean impervious; twenty years ago it was common place to have only one bathroom and no shower [8,40]. Practices are open-ended, many participants could recollect a time where they did things differently, whether it was an effect of location, personal circumstance. Furthermore practices were exposed to temporary interruption, either voluntarily (e.g. holidays and family visits) or technological/infrastructural failure (e.g. burst mains/ boiler problems).

"We had a boiler problem lasting for six months and we very often didn't have hot water at all [...] It got to the point where I boiled kettles and washed my hair in the sink" (Vladi, 40).

In some cases these interruptions would yield sustainable benefits however in pursuit of normality these were generally limited, shortlived and localized.

Current regulations and standards (e.g. guaranteed minimum standards of service - 
GSS) protect consumers from supply interruptions however the findings from this research suggest that such interruptions may provide moments for consumers to reflect on habits and routines, and potential opportunities for new practices to be experienced, if not established in the long term. While creating disruption may be unethical and the mechanisms to protect consumers are well-intended, these findings highlight a role for the water industry in reconfiguring standards of 'normal' and acceptable use. In particular there is a role for the water industry in supporting and engaging with designers, manufacturers and retailers as well as working with the media that shapes consumer expectations and experiences. It is important that actions taken to design sustainable technologies and homes work with their users previous research demonstrates when this is not the case that technologies risk being appropriated by their users with unanticipated consequences [41-43].

The second finding from the discussions was the relational nature of practices which connect across different activities and spaces in everyday life. Rather than simply doing the laundry participants were washing uniforms ready for work the next day, cleaning bedding and baby cloths, or washing dirty sports kit. The context of these sub-practices is significant, for example one participant was a car-part manufacturer handling "parts coming from all over the world with all sorts of dust and stuff on them", yet the company they supplied to require staff to wear white overalls, requiring daily washing to prevent them becoming "manky and horrible". This had considerable bearing on laundry for workers at the warehouse particularly those, unlike himself, who only had one over-coat.

"I know loads of my associates they wash theirs regularly, luckily because I control the budget l've factored in extra uniform for myself so l've one for everyday" (Stephen, 31).

Treating demand as the effect of socio-technical practices is complex, but it reveals invaluable opportunities for new forms of intervention. Collective conventions around home-making, convenience, and 'modern life' all bear considerable influence on water consumption which will not be shifted through information and messaging as they are subtle and diffuse processes experienced throughout everyday life. From this perspective achieving sustainable domestic water consumption about reconfiguring normal, not only at an individual and household level but how it is engrained in everyday practices such as parenting, working and relaxing. These findings suggest the most useful starting point is to explore behaviors such as showering and laundry as multiple, relational practices.

\section{DISCUSSION: WHAT DOES THIS MEAN FOR HOW WE INTERVENE?}

The previous section summarizes the strengths and weaknesses of the four perspectives presented in section 2 and their capacity to elicit change in water use in the home, according to the experiences of customers in the south of England. The following paragraphs explore how this evidence might inform intervention and shape future water efficiency activities. The emphasis here is placed on laundry as one of the most resource intensive water consuming activities in the home, however similar 'thought experiments' could be conducted with the full range of water efficiency practices (as explored in a range of workshops with the UK Water Industry in 2015 [44]). In this instance discussions reveal how a more comprehensive understanding of behavior identifies a wider range of potential intervention strategies, offering insights for the UK water industry. Many of the insights presented here are transferrable, offering meaningful reflections on the practices of resource management other geographic and substantive contexts.

Laundry accounts for approximately $9 \%$ of all domestic water use, with the average household carrying out 4.7 washes per week [20]. It is an important resource consuming activity not only for water but also for energy use and is a common target for efficiency activities as there are a number of potential changes to technology and behavior that could be beneficial. Common aims include reducing the number of washes, ensuring that washer loads are full, improving the efficiency of washers (and dryers) and encouraging the use of 'eco-settings' and low temperatures. From an energy perspective there are also aims to shift the timing of washing to reduce peak loads.

From a service provision perspective, potential management actions could be taken to ration water use; limiting the timing, frequency or mode of laundry however our findings suggest this is unlikely to be supported by customers. A further 
option might be to shift towards technological efficiency by regulating manufacturing; making At++ machines the industry standard and 'eco' the default setting. There are activities ongoing in both the water and energy industry to encourage the standardization of appliances however this is predominantly through voluntary agreements rather than regulation. There is however precedence for regulation of this type, for example in 2009 the European Union announced that incandescent light bulbs would be phased out. Building upon pre-established voluntary agreements the UK structured a program for their removal from the market by 2011.

The short term impacts of such activities may be substantial, however alone are unlikely to be sufficient to bring about sustainable water use. Shove [36] demonstrates that patterns of clothes washing have changed significantly over the last century. Compared to a tradition of weekly washing, the average of 4.7 washer loads a week reported above is a remarkable increase in frequency of washing. Another notable trend is the shift from boil-washing to modern washing in which average settings are $40-50^{\circ} \mathrm{C}$. Furthermore there is evidence to suggest we now wash for convenience rather than cleanliness or hygiene [27], the consequence of this being the increased tendency towards partially full washer loads. These long term trends are problematic as while enhancing the technological efficiency of washing machines will offer benefits, without engaging with such patterns of practice these will not be optimized and in the long term likely to be offset by increasing frequency of washing.

The decision making and social norms perspectives offer two potential routes to intervene in the collective drivers of laundry. The former promoting water, energy and money savings to make reduced consumption common sense, the latter using social comparison through mechanism such as informed billing or normative messaging (e.g. "The majority of people wear their jeans at least 10 times before washing them" Icaro Consulting, 2013, p.55). Providing consumers with information and incentives is becoming increasingly common $[5,6,45]$, particularly with an aim to reduce the temperature of washing and to ensure that machines are full. The participants in the current research were all familiar with these ideas, which is consistent with research that suggests information may positively impact on awareness and intention. However there is further research that suggests that intentions poorly translate into action [19], meaning the potential savings of this activity go unrealized. A further opportunity informed by the social norms and networks perspective is to target specific communities. There is precedence for such an approach, for example Thames Water's fit to drink campaign worked with members of the Muslim women's collective to deliver campaign messages through sermons, community events and social media. This campaign demonstrated the benefits discussed above, improving the knowledge, confidence and skills of the wider community, however focus group discussion reveals water consumption to be habitual and constrained by technologies such as appliances and clothing which reduce the efficacy of such campaigns.

Hobson [22] describes stronger forms of sustainable consumption as those that elicit more substantial reorganization of social, infrastructural/technological, and economic systems. Using the fourth perspective laundry becomes a fragmented socio-technical practice. There is washing to clean (e.g. sports kit), washing to freshen (e.g. black leggings), washing for hygiene (e.g. bedding and towels) and washing for work (e.g. uniform) each posing different opportunities for intervention. In the example above, the stipulation of white overalls for employees of a car-part manufacturing warehouse generates several washes a week. Here is a highly resource intensive sub-practice to which intervention might be targeted, and there are numerous paths that may be taken. Firstly workers may be provided with extra uniforms to enable them, like Stephen, to reduce the number of washes required in a week. However this doesn't alter how regularly uniform requires washing, merely generates more of it to enable it to be less intensive. As an alternative, through collaboration with employers, dark colored uniforms may be introduced, requiring less frequent washing. There is precedence for action of this nature; the CoolBiz campaign in Japan worked with employers and the fashion industry to establish less formal dress codes in the workplace, allowing employees to dress more suitably for the seasons. This was effective in reducing emissions from air-conditioning [29]. In a further alternative we might shift uniform washing from being a household activity to a workplace activity, posing an opportunity for high volume efficient washing. Combined with dark colored uniform this could significantly reduce the resource intensity of uniform washing. Interventions of this kind are ambitious but achievable, furthermore by interrupting routines 
in this way we potentially gain access to networks of practices, for instance workers getting changed at the end of the day may be more inclined to take up cycling as they are already changing out of their clothes leading to contributing toward other sustainability agendas.

\section{CONCLUSIONS}

This paper began with two key questions: how can we understand water consumption as a collectively ordered activity? And how can we use the collective drivers of consumption to reduce household water demand? Through a critical analysis of the literature and focus group research we have demonstrated the value of a multi-perspective approach to unravel complex, entangled practices of everyday water consumption and the implications of this perspective on shaping different insights into water efficiency programs. The synopsis of developments across the social sciences enabled the side-by-side discussion of different perspectives which are traditionally distant within the literature. The focus groups enabled assessment of the suitability and efficacy of these four perspectives to inform intervention and bring about sustainable domestic water consumption.

The benefits of taking a multi-perspective approach to understanding water efficiency and water demand is to favor breadth over depth in order to creatively explore potential solutions to complex problems. In taking such an approach we have identified useful starting points for further research and designing intervention within the water industry, using the example of laundry. Firstly domestic water consumption must be understood as relational; while taking place in the home, it connects to different spatial and temporal sites and scales, actors and activities. Secondly practices of domestic consumption are multiple; connecting variously to practices of parenting, working, cleaning and recreation, each with their own relational entanglements.

There is a growing body of research that makes similar observations in other areas of resource consumption like energy use (most notably from theories of social practice). Further applied research may be usefully directed toward supporting the development of a multiperspective approach to water demand and generating a more holistic understanding of household water consumption to guide intervention. Just as important is that water efficiency interventions are designed to reflect these wider developments and that policy and regulation are developed in ways that support this. This research has highlighted that domestic water consumption is messy and complex, and achieving sustainability related to water consumption equally so. Creating interventions that engage with the multiple perspectives highlighted in this research (Table 1) will require creative experimentation, and creating innovative systems of measurement and monitoring, flexible timescales against which to chart savings, and a sense of how to 'scale' interventions.

\section{ACKNOWLEDGEMENTS}

The authors wish to acknowledge the ESRC and Thames Water for funding the NWDTC ESRC CASE doctoral scholarship to which this research contributes (ES/J500094/1). In addition the authors thank Alice Bows-Larkin (Tyndall Centre for Climate Change Research, University of Manchester) and Rosie Rand (Thames Water) for comments on early drafts.

\section{COMPETING INTERESTS}

Authors have declared that no competing interests exist.

\section{REFERENCES}

1. Brooks DB. An operational definition of water demand management. International Journal of Water Resources Development. 2006;22(4):521-528.

DOI: $10.1080 / 07900620600779699$.

2. Defra. Water for Life.; 2011. Available:https://www.gov.uk/government/u ploads/system/uploads/attachment data/fil e/228861/8230.pdf

3. Shove E. Beyond the ABC: Climate change policy and theories of social change. Environment and Planning $A$. 2010;42(6):1273-1285.

DOI: $10.1068 / \mathrm{a} 42282$

4. Chappells $H$, Medd W. From big solutions to small practices. Social Alternatives. 2008;27(3):44-49.

5. Strengers Y. Negotiating everyday life: The role of energy and water consumption feedback. Journal of Consumer Culture. 2011;11(3):319-338.

DOI: $10.1177 / 1469540511417994$

6. Sofoulis Z. Skirting complexity: The retarding quest for the average water user. Continuum: Journal of Media \& Cultural Studies. $2011 ; 25(6): 795-810$. 
7. Shove E. Comfort, cleanliness and convenience: The social organization of normality. Oxford: Berg Publishers; 2003.

8. Hand M, Shove E, Southerton D. Explaining showering: A discussion of the material, conventional, and temporal dimensions of practice. Sociological Research Online. 2005;10:2.

9. Pullinger M, Browne A, Anderson B, Medd W. Patterns of water: The water related practices of households in Southern England, and Their Influence on Water Consumption and Demand Management.; 2013.

Available:http://www.sprg.ac.uk/uploads/pa tterns-of-water-final-report.pdf

10. Browne A, Medd W, Pullinger M, Anderson B. Distributed demand and the sociology of water efficiency. In: Adeyeye K, ed. Water Efficiency in Buildings: Theory and Practice. John Wiley \& Sons. 2014;74-84.

11. Shove E. Putting practice into policy: reconfiguring questions of consumption and climate change. Contemporary Social Science: Journal of the Academy of Social Sciences. 2012;1-15.

DOI: $10.1080 / 21582041.2012 .692484$

12. Spurling N, Mcmeekin A, Shove $E$, Southerton D, Welch D. Interventions in practice: Re-framing policy approaches to consumer behaviour; 2013.

Available:http://www.sprg.ac.uk/projectsfellowships/theoretical-development-andintegration/interventions-in-practice---sprgreport

13. Bakker K. The limits of "neoliberal natures": Debating green neoliberalism. Progress in Human Geography. 2010; 34(6):715-735.

DOI: $10.1177 / 0309132510376849$.

14. Bakker KJ. Privatizing water, producing scarcity: The yorkshire drought of 1995. Economic Geography. 2012;76(1):4-27.

15. Taylor V, Trentmann F. Liquid politics: Water and the politics of everyday life in the modern city. Past \& Present. 2011; 211(1):199-241.

16. Graham S, Marvin S. Splintering Urbanism. $2^{\text {nd }}$ ed. London and New York: Routledge; 2002.

17. Brown R, Keath N, Wong T. Transitioning to water sensitive cities: historical, current and future transition states. In: $11^{\text {th }}$ International Conference on Urban Drainage, Edinburgh, Scotland, UK. 2008; 1-10.
18. Clarke N. Inhuman nature: Sociable life on a dynamic planet. London: SAGE Publications Ltd; 2011.

19. Russell S, Fielding K. Water demand management research: A psychological perspective. Water Resources Research. 2010;46(5):1-12.

DOI: 10.1029/2009WR008408

20. Energy Saving Trust. At Home with Water.; 2013.

Available:http://www.energysavingtrust.org .uk/About-us/The-Foundation/At-Homewith-Water

21. Jackson T. Motivating sustainable consumption: A Review of Evidence on Consumer Behaviour and Behavioural Change.; 2005.

Available:http://www.sustainablelifestyles.a c.uk/sites/default/files/motivating sc final.p df

22. Hobson K. "Weak" or "strong" sustainable consumption? Efficiency, degrowth, and the 10 year framework of programmes. Environment and Planning C: Government and Policy. 2013;31(6):1082-1098.

DOI: $10.1068 / \mathrm{c} 12279$

23. Clark W, Finley J. Determinants of Water Conservation Intention in Blagoevgrad, Bulgaria. Society \& Natural Resources. 2007;20(7):613-627.

DOI: $10.1080 / 08941920701216552$

24. Lam SP. Predicting intention to save water: Theory of planned behavior, response efficacy, vulnerability, and perceived efficiency of alternative solutions 1 . Journal of Applied Social Psychology. 2006;36(11): 2803-2824.

25. Corral-Verdugo V, Carrus G, Bonnes M, Moser G, Sinha JBP. Environmental beliefs and endorsement of sustainable development principles in water conservation: Toward a new human interdependence paradigm scale. Environment and Behavior. 2008;40(5): 703-725.

DOI: $10.1177 / 0013916507308786$

26. Schultz PW, Shriver C, Tabanico JJ, Khazian AM. Implicit connections with nature. Journal of Environmental Psychology. 2004;24(1):31-42.

DOI: 10.1016/S0272-4944(03)00022-7

27. Jack T. Nobody was dirty: Intervening in inconspicuous consumption of laundry routines. Journal of Consumer Culture. 2013;13(3):406-421.

DOI: $10.1177 / 1469540513485272$. 
28. Shove E, Pantzar M. Consumers, Producers and Practices: Understanding the invention and reinvention of Nordic walking. Journal of Consumer Culture. 2005;5(1):43-64.

DOI: $10.1177 / 1469540505049846$

29. Shove E, Pantzar M, Watson M. The dynamics of social practice: Everyday life and how it changes. SAGE Publications. 2012;191.

30. HM Government, Defra. Future Water.; 2008.

Available:https://www.gov.uk/government/u ploads/system/uploads/attachment data/fil e/69346/pb13562-future-water-080204.pdf

31. Taylor V, Chappells H, Medd W, Trentmann F. Drought is normal: The socio-technical evolution of drought and water demand in England and Wales, 1893-2006. Journal of Historical Geography. 2009;35(3):568-591.

32. Haughton G. Private profits - public drought: The creation of a crisis in water management for West Yorkshire. 1998; 23(9):419-433.

33. Bakker KJ. From public to private to ... mutual? Restructuring water supply governance in England and Wales. Geoforum. 2003;34(3):359-374.

DOI: 10.1016/S0016-7185(02)00092-1.

34. Sofoulis Z. Big water, everyday water: A sociotechnical perspective. Continuum: Journal of Media \& Cultural Studies. 2005; 19(4):445-463.

DOI: $10.1080 / 10304310500322685$

35. Marvin S, Medd W. Metabolisms of obecity: Flows of fat through bodies, cities, and sewers. Environment and Planning $A$. 2006;38(2):313-324.

DOI: $10.1068 / \mathrm{a} 37272$

36. Shove E. Inconspicuous consumption: The sociology of consumption and the environment. In: Dunlap $\mathrm{R}$, ed. Sociological theory and the environment: Classical foundations, contemporary insights. Lanham, Md.: Rownan and Littlefield Publishers. 2001;230-241.

37. Hitchings R. People can talk about their practices. Area. 2012;44(1):61-67.

DOI: 10.1111/j.1475-4762.2011.01060.x.

38. Day R, Hitchings R. Only old ladies would do that: Age stigma and older people's strategies for dealing with winter cold. Health \& Place. 2011;17(4):885-894.

DOI: 10.1016/j.healthplace.2011.04.011

39. Icaro consulting. Understanding Household Water Behaviours and Testing Water Efficiency Messages.; 2013.

Available:http://randd.defra.gov.uk/Default. aspx?Menu=Menu\&Module=More\&Locatio $\underline{\mathrm{n}=\text { None\&Completed }=0 \text { \&Project } \mid \mathrm{D}=18305}$

40. Hand M, Shove E, Southerton D. Home extensions in the United Kingdom: Space, time, and practice. Environment and Planning D: Society and Space. 2007; 25(4):668-681.

DOI: $10.1068 / \mathrm{d} 413 \mathrm{t}$

41. Kuijer L. Implications of Social Practice Theory for Sustainable Design. 2014. Available:http://studiolab.ide.tudelft.nl/studi olab/kuijer/thesis/

42. Gram-Hanssen K. Retrofitting owneroccupied housing: Remember the people. Building Research \& Information. 2014; 42(4):393-397.

DOI: 10.1080/09613218.2014.911572

43. Vlasova L, Gram-Hanssen K. Incorporating inhabitants' everyday practices into domestic retrofits. Building Research \& Information. 2014;42(4):512-524.

DOI: 10.1080/09613218.2014.907682

44. Hoolohan C. Innovative behaviour change strategies for water efficiency in the UK. In: Water Efficiency Network Proceedings; 2015.

45. Hobson K. Competing discourses of sustainable consumption: Does the "Rationalisation of Lifestyles" make sense? Environmental Politics. 2002;11(2):95-120. DOI:10.1080/714000601

(C) 2016 Hoolohan and Browne; This is an Open Access article distributed under the terms of the Creative Commons Attribution License (http://creativecommons.org/licenses/by/4.0), which permits unrestricted use, distribution, and reproduction in any medium, provided the original work is properly cited. 